\title{
The major causes and risk factors of total and cause-specific mortality during 5.4-year follow-up: the Shanghai Changfeng Study
}

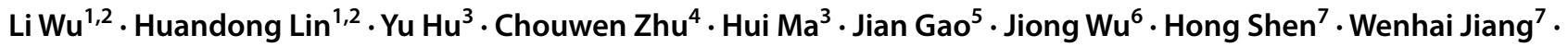 \\ Naiqing Zhao ${ }^{8}$. Yiqing Yin ${ }^{7}$. Baishen Pan $^{6}$. Johannes Jeekel ${ }^{9} \cdot$ Albert Hofman $^{10} \cdot$ Xin Gao $^{1,2,11}$
}

Received: 29 September 2018 / Accepted: 26 July 2019 / Published online: 1 August 2019

(c) The Author(s) 2019

\begin{abstract}
To investigate the major causes and predictive factors of death in a middle-aged and elderly Chinese population. A total of 6591 residents aged $\geq 45$ years from Shanghai Changfeng community were followed up for an average of 5.4 years. The causes of death were coded according to the 10th Revision of International Classification of Diseases. The mortality rate was calculated by person-years of follow up and age-standardized according to the 2010 Chinese census data. Multivariableadjusted Cox proportional hazards model was performed to investigate the predictors of all-cause and cause-specific mortality. During the total follow-up of 35,739 person-years, 370 deaths were documented ( 157 from malignant neoplasms, 70 from heart diseases, 68 from cerebrovascular diseases, 75 from other causes). The age-standardized all-cause mortality rate was 798.2 per 100,000 person-years (927.9 among men and 716.7 among women). Results from multivariable analyses showed that aging, diabetes, and osteoporosis at baseline were independent predictors of all-cause mortality, with hazard ratios (HR) of 1.11 (95\% CI 1.10-1.13), 1.91 (1.51-2.42), and 1.71 (1.24-2.35), respectively. The population attributable risk percent of diabetes and osteoporosis was $19.7 \%$ and $11.7 \%$, respectively. Cigarette smoking was associated with a higher risk of allcause mortality in men (HR and 95\% CI 1.44, 1.01-2.06). In women, diabetes and osteoporosis were related to a higher risk of cardiovascular mortality $(3.27,1.82-5.88$ and $1.89,1.04-3.46$, respectively). While in men, osteoporosis was related to a higher risk of malignant neoplasms mortality $(2.39,1.07-5.33)$. Malignant neoplasms, heart diseases, and cerebrovascular diseases are the leading causes of death. Aging, smoking, underweight, diabetes, and osteoporosis are independent predictors of premature death among middle-aged and elderly Chinese community population. Moreover, there may have been some differences in the causes and predictors of premature death between men and women.
\end{abstract}

Keywords Causes of death $\cdot$ Risk factors $\cdot$ Middle-aged and elderly Chinese population

Li Wu and Huandong Lin have contributed equally to this work.

Xin Gao

happy20061208@126.com; zhongshan_endo@126.com

1 Department of Endocrinology and Metabolism, Zhongshan Hospital, Fudan University, Shanghai 200032, China

2 Fudan Institute for Metabolic Diseases, Shanghai 200032, China

3 Department of Geriatrics, Zhongshan Hospital, Fudan University, Shanghai 200032, China

4 Department of Gastroenterology, Zhongshan Hospital, Fudan University, Shanghai 200032, China

5 Department of Clinical Nutrition, Zhongshan Hospital, Fudan University, Shanghai 200032, China

6 Department of Laboratory Medicine, Zhongshan Hospital, Fudan University, Shanghai 200032, China
7 Network Information Center, Zhongshan Hospital, Fudan University, Shanghai 200032, China

8 Department of Biostatistics, School of Public Health, Fudan University, Shanghai 200032, China

9 Department of Neuroscience, Erasmus Medical Center, Rotterdam, The Netherlands

10 Department of Epidemiology, Harvard T.H. Chan School of Public Health, Boston, MA, USA

11 State Key Laboratory of Genetic Engineering, Human Phenome Institute and School of Life Sciences, Fudan University, Shanghai, China 


\section{Introduction}

Globally, rapid economic development and improvement in living conditions, nutrition, and health care have resulted in declines in infant mortality and deaths from infectious diseases and increases in life expectancy during the past three decades $[1,2]$. In contrast, urbanized lifestyle (calorie-dense diet and sedentary environment) accompanied with the aging population have led to the rapid rise in prevalence of chronic non-communicable diseases (NCDs), such as cardiovascular diseases, cancers, chronic pulmonary diseases, and diabetes mellitus [3]. The Global Burden of Diseases Study 2016 (GBD 2016) reported that mortality due to NCDs increased from $57 \%$ of total mortality in 1990 to $72.3 \%$ in 2016 [1]. In China, with remarkable economic and social development, the life expectancy at birth increased by 8.5 years from 1990 to 2013 [4], and NCDs caused mortality has increased from 69.2 to $86.6 \%$ of the total annual deaths during the same period [5].

Changes in mortality and its main causes are important indicators of national health. China has been undergoing tremendous demographic and epidemiological transitions during the past three decades, but the leading health problems differ across different regions [5]. Local health policies are needed to be made to deal with the diverse challenges faced by local health-care systems. With the improvement of the death surveillance system, investigation of death causes and risk factors have become possible [6].

However, most previous death investigations were conducted among the whole population, the surveys focused on middle-aged and elderly population were limited. Gu et al. [7] ever estimated the major causes and preventable risk factors of mortality among Chinese adults aged 40 years or older from 1991 to 2000. Since then, there were few studies estimating the causes and risk factors for mortality among Chinese middleaged and elderly population, and most of the existing ones were conducted in a specific population, such as the retired military veterans [8] or male steelworkers [9]. Shanghai is one of the most developed cities in China, the aging tendency of its population is more severe than most other Chinese cities. Valid information on mortality and its modifiable risk factors is crucial for health policy to set priority for the prevention of premature death. In this study, using data from the Shanghai Changfeng study [10,11], we aimed to investigate the major causes and predictive factors of premature death in a Chinese community population aged 45 years and older.

\section{Methods}

\section{Study population}

The participants were from Shanghai Changfeng Study, a prospectively observational community-based cohort study, which is focused on chronic diseases among the middle-aged and elderly. Details of the study information have been described elsewhere [10]. The Changfeng community is a middle-class community located in the north-west part of Shanghai. The inclusion criteria of participants were: (1) aged 45 years or older, (2) lived in Changfeng community for at least 5 years. Our study population can represent the general adult population aged 45 years or older in Shanghai. From June 2009 to December 2012, 6595 residents were enrolled. During the follow-up period, 4 participants missing the vital status record were excluded. Eventually, 6591 individuals were included in our final analyses. This study was approved by the ethical committee of Zhongshan Hospital affiliated to Fudan University and informed consent was obtained from all individual participants.

\section{Baseline examination}

Information on sociodemographic variables, including age, gender, cigarette smoking, and alcohol consumption, were collected through face-to-face interviews using structured questionnaires. The participants were instructed to maintain their usual lifestyle for at least 3 days before each examination. Cigarette smoker was defined as smoking at least one cigarette per day for one or more years. Regular alcohol consumption was defined as the average alcohol consumption of more than $10 \mathrm{~g}$ of absolute alcohol per day for 1 year or longer.

Height and weight were measured with the participants wearing light clothes without shoes. Body mass index (BMI) was calculated as weight in kilograms divided by the square of height in meters $\left(\mathrm{kg} / \mathrm{m}^{2}\right)$. Normal weight was defined as a BMI of 18.5 to $<24.0 \mathrm{~kg} / \mathrm{m}^{2}$, underweight was defined as a BMI of $<18.5 \mathrm{~kg} / \mathrm{m}^{2}$, overweight was defined as a BMI of 24.0 to $<28.0 \mathrm{~kg} / \mathrm{m}^{2}$, and obesity as a BMI of $\geq 28.0 \mathrm{~kg} / \mathrm{m}^{2}$ according to Chinese criteria [12]. Resting blood pressure was measured three 
times in the same arm with an electronic blood pressure monitor (OMRON Model HEM-752 FUZZY, Omron Co., Dalian, China) after the participants had been sitting quietly for at least $5 \mathrm{~min}$, and the average of three measurements was used for analysis. Hypertension was defined as a blood pressure $\geq 140 / 90 \mathrm{mmHg}$ or self-reported current use of antihypertensive medications, and prehypertension was defined as $120 \leq$ systolic blood pressure $(\mathrm{SBP}) \leq 139 \mathrm{mmHg}$ or $80 \leq$ diastolic blood pressure (DBP) $\leq 89 \mathrm{mmHg}$ [13].

Blood samples were collected after a fasting period of at least $10 \mathrm{~h}$. Fasting plasma glucose (FPG), total cholesterol (TC), triglyceride (TG), high-density lipoprotein cholesterol (HDL-C), and low-density lipoprotein cholesterol (LDL-C) were measured using an automated bioanalyzer (HITACHI 7600, Tokyo, Japan). Dyslipidemia was defined as $\mathrm{TC} \geq 6.22 \mathrm{mmol} / \mathrm{L}$, or $\mathrm{TG} \geq 2.26 \mathrm{mmol} / \mathrm{L}$, or LDL-C $\geq 4.14 \mathrm{mmol} / \mathrm{L}$, or HDL-C $<1.04 \mathrm{mmol} / \mathrm{L}$, or self-reported current use of antilipidemic agents [14]. The 2-h plasma glucose (2-h PG) was measured after a $75 \mathrm{~g}$ oral glucose tolerance test (OGTT). Diabetes mellitus (DM) was defined as $\mathrm{FPG} \geq 7.0 \mathrm{mmol} / \mathrm{L}$ or 2-hPG $\geq 11.1 \mathrm{mmol} / \mathrm{L}$ according to the WHO 1999 criteria [15], or a previous diagnosis or self-reported current treatment with hypoglycemic drugs. Pre-diabetes was defined as either impaired fasting glucose (FPG $\geq 6.1$ and $<7.0 \mathrm{mmol} / \mathrm{L})$ or impaired glucose tolerance $(2-\mathrm{h}$ $\mathrm{PG} \geq 7.8$ and $<11.1 \mathrm{mmol} / \mathrm{L})$. All blood samples were measured in the central laboratory of the Zhongshan Hospital affiliated to Fudan University.

Bone mineral density (BMD) at the lumbar spine (L1-L4), femoral neck, and total hip were measured using dual-energy X-ray absorptiometry (GE Healthcare Lunar iDXA system) and conducted by a trained technician. Osteopenia was defined as a $\mathrm{T}$ score of -1.0 to -2.5 standard deviations (SD) and osteoporosis as a $\mathrm{T}$ score $\leq-2.5 \mathrm{SD}$ according to the WHO criteria [16].

\section{Follow-up}

We followed participants from the date of recruitment to the date of death or 31 December 2016, whichever came first. The mean follow-up time was 5.4 years. The vital status of participants was collected from the Shanghai Centers for Disease Control (SCDC), and the causes of death were coded according to the 10th Revision of International Classification of Diseases (ICD-10). The main endpoints during the follow-up were death due to malignant neoplasms (ICD-10 codes C00-C97), heart diseases (ICD-10 codes I10-I52), cerebrovascular diseases (ICD-10 codes I60-I69), diabetes mellitus (ICD-10 codes E10-E14), respiratory diseases (ICD-10 codes J00-J99), digestive diseases (ICD-10 codes K00-K93), dementia (ICD-10 codes F00-F03) and accidents (ICD-10 codes V01-X59). All-cause mortality was defined as death due to any causes. Cardiovascular mortality was defined as death caused by coronary disease, stroke, and peripheral arterial disease. Malignant neoplasms mortality was defined as death due to malignant neoplasms.

\section{Statistical analysis}

Continuous variables were presented as mean \pm standard deviation (SD) and categorical variables were presented as numbers (percentages). $T$ test was used for comparison of continuous variables, whereas the Chi squared test was used for comparisons of categorical variables. The baseline characteristics of participants were compared between men and women.

Participants contributed follow-up time was calculated from the date of recruitment to the date of death or 31 December 2016, whichever came first. Age-standardized mortality was calculated by person-years of follow up and adjusted according to the 2010 census data in China [17]. Multivariable-adjusted Cox proportional hazards model was performed to estimate the hazard ratio (HR) and 95\% confidence interval (95\% CI) of predictive factors for all-cause and cause-specific mortality. Potential confounders included baseline age, gender, alcohol consumption, cigarette smoking, and existing diseases (yes/no) including obesity, diabetes, hypertension, dyslipidemia, and osteoporosis. To further analyze the associations of baseline age, BMI, glucose metabolism, blood pressure, bone mineral density with all-cause mortality, we introduced dummy variables in Cox analyses. Participants were divided into different groups according to age [45-54 (reference), 55-64, 65-74, and $\geq 75$ years old], BMI $[<18.5,18.5$ to $<24.0$ (reference), 24.0 to $<28.0$, and $\geq 28.0 \mathrm{~kg} / \mathrm{m}^{2}$ ], glucose metabolism [Normal (reference), Pre-DM, New DM, and Prior DM], blood pressure [Normal (reference), Pre-hypertension, New hypertension, and Prior hypertension] and bone mineral density [Normal (reference), Osteopenia, and Osteoporosis], respectively. The HR of all-cause mortality in one group as compared with the reference group was calculated using multivariable-adjusted Cox proportional hazards model. When one of these factors was categorized and analyzed, the other four factors were adjusted, as well as gender, cigarette smoking, alcohol drinking, and dyslipidemia. Stratified analyses according to sex were performed in all multivariable-adjusted Cox analyses. Population attributable risk percent (PAR\%) was calculated following the formula: $\mathrm{PAR} \%=\mathrm{P}_{\mathrm{e}}(\mathrm{RR}-1) /\left[1+\mathrm{P}_{\mathrm{e}}(\mathrm{RR}-1)\right]$ [18], where $\mathrm{P}_{\mathrm{e}}$ represented the proportion of exposure in the total population, and HR was considered as RR in Cox analysis. All analyses were performed using SPSS version 19.0. Statistical tests were two-sided and a $P<0.05$ was considered statistically significant. 
Table 1 Baseline characteristics of participants

\begin{tabular}{llllr}
\hline & Total $(\mathrm{N}=6591)$ & Men $(\mathrm{N}=2804)$ & Women $(\mathrm{N}=3787)$ & $P$ \\
\hline Age $($ years $)$ & $63.7 \pm 9.7$ & $64.5 \pm 9.8$ & $63.0 \pm 9.6$ & $<0.001$ \\
BMI $\left(\mathrm{kg} / \mathrm{m}^{2}\right)$ & $24.3 \pm 3.3$ & $24.5 \pm 3.1$ & $24.1 \pm 3.5$ & $<0.001$ \\
WC $(\mathrm{cm})$ & $84.0 \pm 9.7$ & $87.0 \pm 9.2$ & $81.9 \pm 9.5$ & $<0.001$ \\
SBP $(\mathrm{mmHg})$ & $135.8 \pm 19.2$ & $137.2 \pm 18.3$ & $134.7 \pm 20.0$ & $<0.001$ \\
DBP $(\mathrm{mmHg})$ & $76.3 \pm 10.2$ & $78.4 \pm 10.3$ & $74.8 \pm 9.8$ & $<0.001$ \\
TC $(\mathrm{mmol} / \mathrm{L})$ & $5.07 \pm 0.94$ & $4.76 \pm 0.88$ & $5.29 \pm 0.92$ & $<0.001$ \\
TG $(\mathrm{mmol} / \mathrm{L})$ & $1.71 \pm 1.23$ & $1.72 \pm 1.26$ & $1.70 \pm 1.20$ & 0.601 \\
HDL-C $(\mathrm{mmol} / \mathrm{L})$ & $1.43 \pm 0.38$ & $1.29 \pm 0.32$ & $1.53 \pm 0.38$ & $<0.001$ \\
LDL-C (mmol/L) & $2.89 \pm 0.81$ & $2.72 \pm 0.76$ & $3.01 \pm 0.81$ & $<0.001$ \\
FPG (mmol/L) & $5.63 \pm 1.55$ & $5.75 \pm 1.70$ & $5.54 \pm 1.43$ & $<0.001$ \\
2-h PG (mmol/L) & $7.63 \pm 3.31$ & $7.86 \pm 3.45$ & $7.47 \pm 3.19$ & $<0.001$ \\
Smokers, $\mathrm{n}(\%)$ & $1496(22.7)$ & $1415(50.6)$ & $81(2.1)$ & $<0.001$ \\
Regular alcohol consumers, $\mathrm{n}(\%)$ & $1089(16.6)$ & $948(33.9)$ & $141(3.7)$ & $<0.001$ \\
Existing diseases & & & & 0.241 \\
Obesity, n (\%) & $806(12.4)$ & $327(11.8)$ & $479(12.8)$ & $<0.001$ \\
Diabetes, n (\%) & $1448(22.3)$ & $703(25.4)$ & $745(19.9)$ & $<0.001$ \\
Hypertension, $\mathrm{n}(\%)$ & $3636(55.6)$ & $1674(60.2)$ & $1962(52.2)$ & 0.003 \\
Dyslipidemia, $\mathrm{n}(\%)$ & $2172(33.1)$ & $979(35.1)$ & $1193(31.6)$ & $<0.001$ \\
Osteoporosis, n (\%) & $576(9.4)$ & $71(2.7)$ & $505(14.3)$ & \\
\hline
\end{tabular}

Data are presented as mean \pm standard deviations or as number (percentage)

$B M I$ body mass index, $W C$ waist circumference, $S B P$ systolic blood pressure, $D B P$ diastolic blood pressure, $T C$ total cholesterol, $T G$ triglyceride, $L D L-C$ low-density lipoprotein cholesterol, $H D L-C$ high-density lipoprotein cholesterol, $F P G$ fasting plasma glucose, $2-h P G$ 2-hour plasma glucose in 75 -g oral glucose tolerance test

\section{Results}

\section{Baseline characteristics and major causes of death in the study population}

As shown in Table 1, the mean age of participants was 63.7 years (46.0-95.8 years) at baseline, and $42.5 \%$ of them were men. Compared to women, men were more likely to be cigarette smokers or alcohol consumers, to have hypertension, dyslipidemia or diabetes, but less likely to have osteoporosis (all $P<0.001$ ).

During the mean follow-up of 5.4 years $(35,739$ personyears in total), we have documented 370 deaths, including 157 from malignant neoplasms, 70 from heart diseases, 68 from cerebrovascular diseases, 26 from diabetes, 11 from respiratory diseases, 10 from digestive diseases, 8 from accidents, 3 from dementia, and the rest from other causes. The age-standardized mortality rate was 798.2 per 100,000 person-years (927.9 per 100,000 person-years among men and 716.7 per 100,000 person-years among women). Age-standardized mortality rate and the percentage of total deaths for the eight leading causes of death are shown in Table 2. Overall, the three leading causes of death (malignant neoplasms, heart diseases, and cerebrovascular diseases) accounted for $79.7 \%$ of total deaths $(76.2 \%$ among men and $84.3 \%$ among women). The distribution of most cause-specific mortality was similar between men and women, except for mortality from respiratory diseases and accidents, which were higher in men than women. Moreover, the five leading causes of death from malignant neoplasms were cancer of the lung, colon and rectum, liver, stomach, and prostate in men, and cancer of the lung, colon and rectum, stomach, breast, and ovary in women (Fig. 1).

\section{Predictors of all-cause mortality}

The multivariable-adjusted HR and PAR\% of all-cause mortality for major predictive factors are shown in Table 3. Aging was the independent predictor of all-cause mortality, with an HR of 1.11 (95\% CI1.10-1.13) per 1-year increment. Diabetes was responsible for $19.7 \%$ of the total mortality, with an HR of 1.91 (95\%CI 1.51-2.42). In participants with diabetes, the risk of all-cause mortality was higher among women than men (HR 2.34 vs. 1.61). Osteoporosis accounted for $11.7 \%$ of the total mortality, with an HR of 1.71 (95\% CI 1.24-2.35). Cigarette smoking significantly increased the risk of all-cause mortality among men, with an HR of 1.44 (95\%CI 1.01-2.06) and PAR\% of 53.5\%. However, the presence of hypertension, obesity or dyslipidemia at baseline was not associated with the increased risk of all-cause mortality in our study. 
Table 2 Age-standardized mortality and the percentage of total deaths for the eight leading causes of death in the middle-aged and elderly Chinese population

\begin{tabular}{|c|c|c|c|c|c|}
\hline Cause of death ${ }^{\mathrm{a}}$ & No. of deaths & $\begin{array}{l}\text { Mortality (per 100,000 } \\
\text { person-year) }\end{array}$ & $\begin{array}{l}\text { Age-standardized mortality (per } \\
100,000 \text { person-year) }^{\mathrm{b}}\end{array}$ & $\begin{array}{l}\text { Percentage of total } \\
\text { deaths }\end{array}$ & Rank order \\
\hline \multicolumn{6}{|l|}{ All causes } \\
\hline Total & 370 & 1035.3 & 798.2 & 100.0 & - \\
\hline Men & 210 & 1399.0 & 927.9 & 100.0 & - \\
\hline Women & 160 & 773.0 & 716.7 & 100.0 & - \\
\hline \multicolumn{6}{|c|}{ Malignant neoplasms } \\
\hline Total & 157 & 439.3 & 312.1 & 42.4 & 1 \\
\hline Men & 87 & 579.6 & 370.0 & 41.4 & 1 \\
\hline Women & 70 & 338.2 & 263.4 & 43.8 & 1 \\
\hline \multicolumn{6}{|l|}{ Heart diseases $^{c}$} \\
\hline Total & 70 & 195.9 & 170.7 & 18.9 & 2 \\
\hline Men & 36 & 239.8 & 161.6 & 17.1 & 3 \\
\hline Women & 34 & 164.3 & 190.5 & 21.3 & 2 \\
\hline \multicolumn{6}{|c|}{ Cerebrovascular diseases } \\
\hline Total & 68 & 190.3 & 160.2 & 18.4 & 3 \\
\hline Men & 37 & 246.5 & 184.5 & 17.6 & 2 \\
\hline Women & 31 & 149.8 & 154.2 & 19.4 & 3 \\
\hline \multicolumn{6}{|l|}{ Diabetes mellitus } \\
\hline Total & 26 & 72.8 & 51.6 & 7.0 & 4 \\
\hline Men & 15 & 99.9 & 63.8 & 7.1 & 4 \\
\hline Women & 11 & 53.1 & 36.5 & 6.9 & 4 \\
\hline \multicolumn{6}{|c|}{ Respiratory diseases } \\
\hline Total & 11 & 30.8 & 22.9 & 3.0 & 5 \\
\hline Men & 10 & 66.6 & 39.7 & 4.8 & 5 \\
\hline Women & 1 & 4.8 & 2.6 & 0.6 & 8 \\
\hline \multicolumn{6}{|c|}{ Digestive diseases } \\
\hline Total & 10 & 28.0 & 21.2 & 2.7 & 6 \\
\hline Men & 6 & 40.0 & 26.6 & 2.9 & 6 \\
\hline Women & 4 & 19.3 & 15.9 & 2.5 & 5 \\
\hline \multicolumn{6}{|l|}{ Accidents $^{\mathrm{d}}$} \\
\hline Total & 8 & 22.4 & 13.4 & 2.2 & 7 \\
\hline Men & 6 & 40.0 & 21.6 & 2.9 & 7 \\
\hline Women & 2 & 9.7 & 5.1 & 1.3 & 6 \\
\hline \multicolumn{6}{|l|}{ Dementia } \\
\hline Total & 3 & 8.4 & 5.4 & 0.8 & 8 \\
\hline Men & 1 & 6.7 & 2.8 & 0.5 & 8 \\
\hline Women & 2 & 9.7 & 8.2 & 1.3 & 7 \\
\hline \multicolumn{6}{|l|}{ All other causes } \\
\hline Total & 17 & 47.6 & 40.7 & 4.6 & - \\
\hline Men & 12 & 79.9 & 57.3 & 5.7 & - \\
\hline Women & 5 & 24.2 & 40.3 & 3.1 & - \\
\hline
\end{tabular}

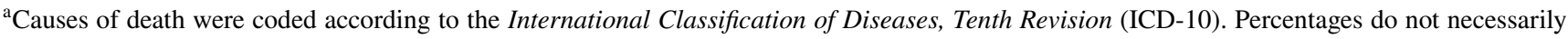
sum to 100 because of rounding

${ }^{\mathrm{b}}$ Age-standardized mortality (per 100,000 person-years) was calculated according to the 2010 census data for China's population

${ }^{c}$ Heart diseases included acute rheumatic fever, chronic rheumatic heart disease, hypertensive disease, ischemic heart disease, diseases of the pulmonary circulation, and other forms of heart disease

${ }^{\mathrm{d}}$ Accidents included vehicular accidents, falls, drowning, and poisoning 
Fig. 1 Age-standardized mortality for the five leading causes of death from malignant neoplasms

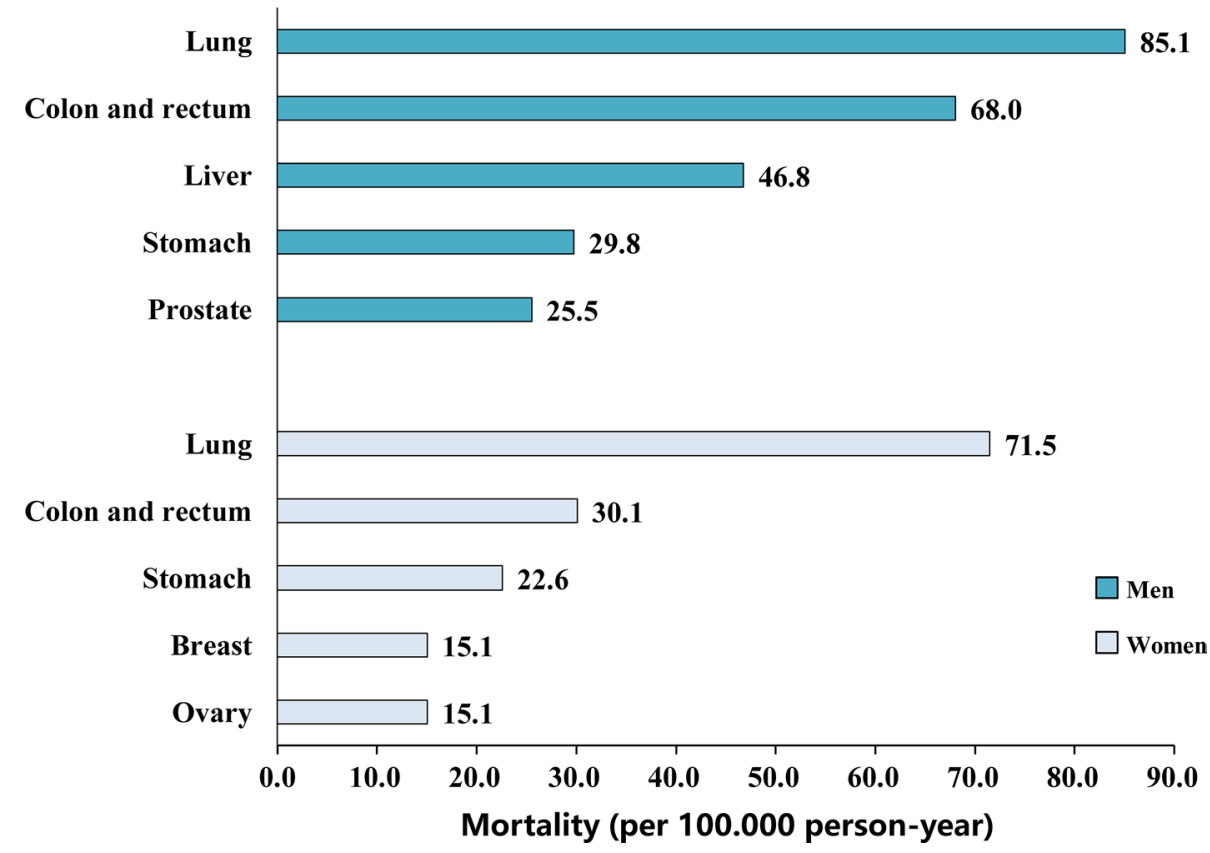

Table 3 Hazard ratio and population attributable risk percent of predictors for all-cause mortality in multivariable-adjusted ${ }^{\mathrm{a}}$ analyses

\begin{tabular}{|c|c|c|c|c|c|c|}
\hline & \multicolumn{2}{|l|}{ Total } & \multicolumn{2}{|l|}{ Men } & \multicolumn{2}{|l|}{ Women } \\
\hline & HR (95\%CI) & PAR $\%$ & HR (95\%CI) & PAR $\%$ & HR $(95 \% \mathrm{CI})$ & PAR\% \\
\hline Age (years) & $1.11(1.10-1.13)$ & - & $1.11(1.09-1.13)$ & - & $1.11(1.09-1.13)$ & - \\
\hline Smoking & $1.29(0.93-1.80)$ & - & $1.44(1.01-2.06)$ & 53.5 & $0.78(0.24-2.57)$ & - \\
\hline Drinking & $1.01(0.72-1.42)$ & - & $0.86(0.59-1.26)$ & - & $2.02(0.96-4.25)$ & - \\
\hline Obesity & $1.18(0.86-1.63)$ & - & $1.27(0.82-1.99)$ & - & $1.10(0.69-1.73)$ & - \\
\hline Diabetes & $1.91(1.51-2.42)$ & 19.7 & $1.61(1.18-2.20)$ & 29.5 & $2.34(1.62-3.37)$ & 12.9 \\
\hline Hypertension & $1.06(0.81-1.40)$ & - & $1.05(0.74-1.51)$ & - & $1.09(0.71-1.68)$ & - \\
\hline Dyslipidemia & $1.08(0.85-1.37)$ & - & $0.97(0.70-1.36)$ & - & $1.23(0.87-1.75)$ & - \\
\hline Osteoporosis & $1.71(1.24-2.35)$ & 11.7 & $2.51(1.50-4.21)$ & 1.8 & $1.48(1.00-2.21)$ & 22.8 \\
\hline
\end{tabular}

$H R$ hazard ratio, $95 \% C I 95 \%$ confidence interval, $P A R \%$ population attributable risk percent

${ }^{a}$ Adjusted for age, gender, cigarette smoking, alcohol drinking, and existing diseases (obesity, diabetes, hypertension, dyslipidemia, and osteoporosis) at baseline
As shown in Table 4, the HR of all-cause mortality in participants aged $\geq 75$ years was nearly 26.6 times of that in participants aged 45-54 years. Participants who were underweight had a significantly higher risk of all-cause mortality than participants with normal weight (HR, 95\%CI 1.73, 1.04-2.88). Osteoporosis independently predicted the risk of all-cause mortality among men, but not among women. Osteopenia could not predict the risk of all-cause mortality either among men or women. However, hypertension still had no significant association with all-cause mortality even we categorized it into pre-hypertension, newly diagnosed hypertension, and prior known hypertension.

\section{Predictors of cardiovascular diseases and malignant neoplasms mortality}

As shown in Table 5, the risk of cardiovascular mortality increased by $13.6 \%$ (12.8\% among men and $15.0 \%$ among women) with per 1-year increase in age. Diabetes and osteoporosis independently predicted the risk of cardiovascular mortality among women, with an HR of 3.27 (95\% CI 1.82-5.88) and 1.89 (95\% CI 1.04-3.46) respectively, but not among men. The risk of malignant neoplasms mortality increased by $9.9 \%$ (9.8\% among men and 9.6\% among women) with per 1-year increase in age. Compared with 
Table 4 Adjusted ${ }^{\text {a }}$ hazard ratio and $95 \%$ confidence interval of all-cause mortality by various characteristics of participants

\begin{tabular}{|c|c|c|c|c|c|c|}
\hline & \multicolumn{2}{|l|}{ Total } & \multicolumn{2}{|l|}{ Men } & \multicolumn{2}{|c|}{ Women } \\
\hline & HR & $95 \% \mathrm{CI}$ & HR & $95 \% \mathrm{CI}$ & HR & $95 \% \mathrm{CI}$ \\
\hline \multicolumn{7}{|l|}{ Age (years) } \\
\hline $45-54^{\text {Ref. }}$ & 1.00 & Ref. & 1.00 & Ref. & 1.00 & Ref. \\
\hline $55-64$ & 3.72 & $1.68-8.26$ & 3.08 & $1.06-8.96$ & 4.95 & $1.38-15.32$ \\
\hline $65-74$ & 9.84 & $4.52-21.43$ & 11.13 & $4.00-31.01$ & 8.03 & $2.41-26.76$ \\
\hline$\geq 75$ & 26.57 & $12.27-57.54$ & 25.61 & $9.22-71.11$ & 27.00 & $8.24-88.45$ \\
\hline \multicolumn{7}{|l|}{ BMI $\left(\mathrm{kg} / \mathrm{m}^{2}\right)$} \\
\hline$<18.5$ & 1.73 & $1.04-2.88$ & 2.04 & $1.08-3.86$ & 1.46 & $0.62-3.44$ \\
\hline 18.5 to $<24.0^{\text {Ref. }}$ & 1.00 & Ref. & 1.00 & Ref. & 1.00 & Ref. \\
\hline 24.0 to $<28.0$ & 0.81 & $0.62-1.05$ & 0.71 & $0.50-1.01$ & 0.98 & $0.65-1.48$ \\
\hline$\geq 28.0$ & 1.07 & $0.76-1.52$ & 1.09 & $0.68-1.76$ & 1.09 & $0.65-1.82$ \\
\hline \multicolumn{7}{|l|}{ Glucose metabolism } \\
\hline Normal $^{\text {Ref. }}$ & 1.00 & Ref. & 1.00 & Ref. & 1.00 & Ref. \\
\hline Pre-DM & 1.11 & $0.81-1.51$ & 1.11 & $0.74-1.66$ & 1.11 & $0.68-1.81$ \\
\hline New DM & 1.80 & $1.30-2.49$ & 1.34 & $0.86-2.09$ & 2.46 & $1.51-4.03$ \\
\hline Prior DM & 2.17 & $1.60-2.96$ & 2.02 & $1.35-3.01$ & 2.42 & $1.47-3.97$ \\
\hline \multicolumn{7}{|l|}{ Blood pressure $(\mathrm{mmHg})$} \\
\hline Normal $^{\text {Ref. }}$ & 1.00 & Ref. & 1.00 & Ref. & 1.00 & Ref. \\
\hline Pre-hypertension & 0.90 & $0.54-1.48$ & 0.63 & $0.33-1.20$ & 1.43 & $0.64-3.21$ \\
\hline New hypertension & 0.59 & $0.34-1.03$ & 0.46 & $0.23-0.93$ & 0.84 & $0.34-2.11$ \\
\hline Prior hypertension & 1.11 & $0.70-1.77$ & 0.85 & $0.47-1.53$ & 1.60 & $0.75-3.42$ \\
\hline \multicolumn{7}{|l|}{ Bone mass } \\
\hline Normal $^{\text {Ref. }}$ & 1.00 & Ref. & 1.00 & Ref. & 1.00 & Ref. \\
\hline Osteopenia & 1.25 & $0.96-1.64$ & 1.22 & $0.88-1.70$ & 1.18 & $0.73-1.90$ \\
\hline Osteoporosis & 1.98 & $1.37-2.86$ & 2.72 & $1.59-4.64$ & 1.69 & $0.98-2.90$ \\
\hline
\end{tabular}

$H R$ hazard ratio, $95 \% C I 95 \%$ confidence interval, $B M I$ body mass index, $D M$ diabetes mellitus

${ }^{a}$ Multivariable-adjusted Cox regression analyses, when one of these factors was categorized and analyzed, the other four factors were adjusted, as well as gender, cigarette smoking, alcohol drinking, and dyslipidemia

Ref. The reference group was the $45-54$ years age group, the 18.5 to $<24.0 \mathrm{~kg} / \mathrm{m}^{2}$ group, the normal glucose metabolism group, the normal blood pressure group, and the normal bone mineral density group, respectively

participants with normal glucose regulation, the risk of malignant neoplasms mortality increased by $49 \%$ in patients with diabetes (HR, 95\% CI 1.49, 1.03-2.14). Osteoporosis independently predicted the risk of malignant neoplasms mortality among men, with an HR of 2.39 (95\% CI 1.07-5.33), but not among women.

\section{Discussion}

In the present study, we found that malignant neoplasms, heart diseases, and cerebrovascular diseases were the three leading causes of death and together accounted for approximately four-fifths of the total mortality. After them, diabetes mellitus was the fourth leading cause of death. Aging, smoking, underweight, diabetes, and osteoporosis were the independent predictors of death.
Monitoring the levels and trends in mortality is crucial to determining how societies can address prominent sources for premature death. Our findings provide important implications for public health. In a recent global study [19], Foreman and colleagues developed a new model and used data from the GBD 2016 study [1] to forecast life expectancy, allcause mortality, and risk factors of death from 2016 to 2040. Their results showed that NCDs would account for a higher proportion of years of life lost (YLLs) by 2040 (67.3\% of YLLs [95\% UI 61.9-72.3] globally) than 2016. YLLs were calculated from the sum of each death multiplied by the standard life expectancy at each age. For most countries, prioritizing NCDs and NCD-related risks in health planning and investment decisions has the potential to markedly reduce premature mortality by 2040 . In our study, NCDs (malignant neoplasms, heart diseases, cerebrovascular diseases, and diabetes) were the leading causes of death. These results were mostly consistent with Foreman's study. 
Table 5 Adjusted ${ }^{\mathrm{a}}$ hazard ratio and $95 \%$ confidence interval of predictors for cardiovascular and malignant neoplasms mortality

\begin{tabular}{|c|c|c|c|c|c|c|}
\hline & \multicolumn{2}{|l|}{ Total } & \multicolumn{2}{|l|}{ Men } & \multicolumn{2}{|c|}{ Women } \\
\hline & HR & $95 \% \mathrm{CI}$ & HR & $95 \% \mathrm{CI}$ & HR & $95 \% \mathrm{CI}$ \\
\hline \multicolumn{7}{|c|}{ Cardiovascular mortality } \\
\hline Age (years) & 1.14 & $(1.11-1.16)$ & 1.13 & $(1.09-1.17)$ & 1.15 & $(1.11-1.20)$ \\
\hline Smoking & 1.57 & $(0.90-2.76)$ & 1.77 & $(0.96-3.26)$ & - & - \\
\hline Drinking & 0.88 & $(0.48-1.60)$ & 0.84 & $(0.44-1.61)$ & 0.81 & $(0.11-5.90)$ \\
\hline Obesity & 0.98 & $(0.56-1.72)$ & 1.36 & $(0.65-2.85)$ & 0.65 & $(0.27-1.57)$ \\
\hline Diabetes & 2.03 & $(1.37-3.00)$ & 1.36 & $(0.79-2.34)$ & 3.27 & $(1.82-5.88)$ \\
\hline Hypertension & 1.52 & $(0.91-2.54)$ & 1.86 & $(0.89-3.88)$ & 1.17 & $(0.56-2.42)$ \\
\hline Dyslipidemia & 1.212 & $(0.82-1.80)$ & 1.26 & $(0.73-2.20)$ & 1.10 & $(0.62-1.95)$ \\
\hline Osteoporosis & 1.92 & $(1.16-3.18)$ & 2.31 & $(0.90-5.95)$ & 1.89 & $(1.04-3.46)$ \\
\hline \multicolumn{7}{|c|}{ Malignant neoplasms mortality } \\
\hline Age (years) & 1.10 & $(1.08-1.12)$ & 1.10 & $(1.07-1.13)$ & 1.10 & $(1.06-1.13)$ \\
\hline Smoking & 1.04 & $(0.63-1.73)$ & 1.15 & $(0.67-1.99)$ & 1.12 & $(0.26-4.93)$ \\
\hline Drinking & 1.12 & $(0.67-1.87)$ & 0.90 & $(0.51-1.59)$ & 2.56 & $(0.98-6.67)$ \\
\hline Obesity & 1.25 & $(0.78-1.99)$ & 0.81 & $(0.37-1.80)$ & 1.72 & $(0.93-3.16)$ \\
\hline Diabetes & 1.49 & $(1.03-2.14)$ & 1.50 & $(0.93-2.42)$ & 1.39 & $(0.79-2.45)$ \\
\hline Hypertension & 0.83 & $(0.56-1.22)$ & 0.83 & $(0.50-1.39)$ & 0.86 & $(0.47-1.55)$ \\
\hline Dyslipidemia & 1.23 & $(0.87-1.75)$ & 1.10 & $(0.67-1.81)$ & 1.56 & $(0.93-2.62)$ \\
\hline Osteoporosis & 1.21 & $(0.72-2.03)$ & 2.39 & $(1.07-5.33)$ & 0.93 & $(0.48-1.79)$ \\
\hline
\end{tabular}

$H R$ hazard ratio, $95 \%$ CI $95 \%$ confidence interval

${ }^{a}$ Adjusted for age, gender, cigarette smoking, alcohol drinking, and existing diseases (obesity, diabetes, hypertension, dyslipidemia, and osteoporosis) at baseline
However, diabetes has become the fourth leading cause of death in our population but ranked as the eighth leading cause in Foreman's study. This observation may be due to the substantial increases in the prevalence of diabetes during the past three decades in China, especially among the elderly population. We also found that the distribution of most cause-specific mortality was similar between men and women, except for respiratory diseases and accidents, this may because men are more likely to be cigarette smokers and have traffic accidents than women.

The malignant neoplasm was the first leading cause of death in our study, the five leading causes of death from malignant neoplasms were lung, colon and rectum, liver, stomach, and prostate cancer among men, and lung, colon and rectum, stomach, breast, and ovarian cancer among women. These results were substantially consistent with the Chinese cancer mortality report in 2018 [20]. However, the ratio of mortality caused by malignant neoplasms in our study was higher than that report; this may be because all of our participants were older than 45 years [21]. In China, lung cancer, female breast cancer, stomach cancer, liver cancer, esophageal cancer, as well as colorectal cancer have become the major causes of malignant neoplasm mortality and resulted in severe burden to our society. Efficient interventions and control strategies are urgently needed, such as changing from calorie-dense diet and sedentary lifestyle to fresh fruits and vegetables-rich diet and physically active lifestyle, improving national cancer screening programs for common cancers, and so on.

Diabetes is a well-recognized risk factor for cardiovascular and cerebrovascular diseases worldwide [22-24]. Convincing evidence indicates that diabetes is also associated with increased risk of several malignant neoplasms [25]. Coughlin et al. [26] and Gross et al. [27] found that diabetes was associated with a higher risk of death from colon, liver, and pancreatic cancer. However, the causal relationship between diabetes and malignant neoplasms has not been established, further researches are needed. Since 1980, the prevalence of diabetes has been quadrupled worldwide [28]. In China, the prevalence of diabetes has increased from $0.67 \%$ in 1980 to $11.6 \%$ in 2010 , whereas rates of awareness, treatment, and control remain unacceptably low [29-32]. Our results showed that diabetes was the leading predictive factor of all-cause mortality, cardiovascular mortality, and malignant neoplasms mortality, and diabetes was responsible for $19.7 \%$ of the all-cause mortality. These results were consistent with previous studies which suggested that diabetes was closely associated with death from all causes, cardiovascular diseases, and malignant neoplasms [33-35]. Coughlin et al. [26] and Gross et al. [27] found that diabetes was associated with a higher risk of death from colon, liver, and pancreatic cancer. Even so, the causal relationship between diabetes and malignant neoplasms has not been established, further researches are needed. 
Except for traditional risk factors such as aging, cigarette smoking, underweight, and diabetes, we also found that osteoporosis was an independent predictor of all-cause and malignant neoplasms caused mortality among men, and cardiovascular mortality among women, this observation was not mentioned in the Foreman's study [19]. The association between osteoporosis and death may be mediated by osteoporotic fracture, which has become a major cause of death in the elderly population [36]. Osteoporosis is common in older women because of progressive postmenopausal bone loss due to the decreasing of estrogen levels. Although the prevalence of osteoporosis in men was significantly lower than women whether in our study or other existing data [37], men with osteoporosis might have higher mortality than women [38]. The causes of osteoporosis in men were more complex than that in women, such as androgen deprivation therapy for prostate cancer and alcohol excess. These may partly explain why osteoporosis can predict the risk of malignant neoplasms mortality among men. In line with our results, previous studies also found that osteoporosis was closely associated with the increased risk of cardiovascular diseases and mortality, especially among women [39, 40]. Further studies are needed to elucidate the mechanism of these associations.

In our study, cigarette smokers had a $44 \%$ higher risk of all-cause mortality than those who never smoked among men, but not among women. This is mainly because of the limited statistical power, because much fewer women (2.1\%) smoked than men $(50.6 \%)$ in our population. Our results were consistent with those from several prospective cohort studies and case-control studies conducted in China [41-43]. Underweight was also an independent predictor of all-cause mortality in our population. The risk of allcause mortality increased by $73 \%$ in participants who were underweight than those with normal weight. Underweight reflected malnutrition and was considered as the leading cause of the disease burden in China 15 years ago [44], but now it is mainly caused by unhealthy diets, malignant neoplasms, and other consumptive diseases, all of which can increase the risk of death.

However, hypertension, obesity, and dyslipidemia were not related with the risk of all-cause mortality in our study population; even if we categorized our participants into prehypertension, newly diagnosed hypertension, and previously diagnosed hypertension. We think these may be because most patients with hypertension or dyslipidemia began to take a medication once they were diagnosed, and their blood pressure and serum lipid were controlled within the normal range in most time. One other explanation might be that the follow-up time in our study was not long enough to see the impact of hypertension and dyslipidemia on mortality. The association between obesity and all-cause mortality is still controversial $[45,46]$. This may due to the diagnostic criterion for obesity is different across studies, and most of our obesity participants had a BMI of 28.0 to $<35 \mathrm{~kg} /$ $\mathrm{m}^{2}$, which was considered as mild obesity. Flegal et al. [47] reported that mild obesity (BMI 30 to $<35 \mathrm{~kg} / \mathrm{m}^{2}$ ) was not associated with higher all-cause mortality, their results were consistent with ours.

In the present study, using a large prospective cohort with long-term follow-up, we identified the major causes of death and its predictors in a representative sample of the middleaged and elderly population, providing some guidance for government to make health policies. Nevertheless, a few limitations need to be noticed in our study. Firstly, we did not have autopsy data to confirm the causes of death; this may induce some misclassification bias. However, this is the most practical way in epidemiology studies. Secondly, factors such as education, marital status, social economic status, diet quality, and physical activity were not included in our analyses partially because of missing values, and this will lead to residual confounding. Thirdly, as the death toll was relatively small based on the current follow-up time in our study, the impact of some risk factors on mortality may not be yet apparent, such as hypertension and dyslipidemia.

In conclusion, our study indicated that malignant neoplasms, heart diseases, and cerebrovascular diseases were three leading causes of death in middle-aged and elderly Chinese community population. Moreover, malignant neoplasm has become the first leading cause of death instead of heart diseases, and diabetes has risen to the fourth cause of death. Aging, smoking, underweight, diabetes, and osteoporosis were the independent predictors for premature death, and their effect on death might be different between men and women. Efficient interventions and control strategies are urgently needed, such as changing from calorie-dense diet and sedentary lifestyle to diets rich in fresh fruits and vegetables as well as a physically active lifestyle, and promoting national cancer screening programs for common cancers. Beyond that, prevention and control of diabetes and osteoporosis, quit smoking, and maintain a healthy weight are also very important for reducing the burden of premature mortality.

Acknowledgements We thank Yan Zheng for her professional review and constructive suggestions. This work was supported by the Shanghai Municipal Science and Technology Commission Foundation (Grant No. 16411954800), the Shanghai Municipal Science and Technology Major Project (Grant No. 2017SHZDZX01), and the key basic research grants from Science and Technology Commission of Shanghai Municipality (Grant No. 16JC1400500).

\section{Compliance with ethical standards}

Conflict of interest The authors declare that they have no conflict of interest in relation to this work. 
Open Access This article is distributed under the terms of the Creative Commons Attribution 4.0 International License (http://creativeco mmons.org/licenses/by/4.0/), which permits unrestricted use, distribution, and reproduction in any medium, provided you give appropriate credit to the original author(s) and the source, provide a link to the Creative Commons license, and indicate if changes were made.

\section{References}

1. Naghavi M, Abajobir AA, Abbafati C, Abbas KM, Abd-Allah $\mathrm{F}$, Abera SF, et al. Global, regional, and national age-sex specific mortality for 264 causes of death, 1980-2016: a systematic analysis for the Global Burden of Disease Study 2016. Lancet. 2017;390(10100):1151-210. https://doi.org/10.1016/s0140 $-6736(17) 32152-9$.

2. Wang H, Abajobir AA, Abate KH, Abbafati C, Abbas KM, AbdAllah F, et al. Global, regional, and national under-5 mortality, adult mortality, age-specific mortality, and life expectancy, 1970-2016: a systematic analysis for the Global Burden of Disease Study 2016. Lancet. 2017;390(10100):1084-150. https://doi. org/10.1016/s0140-6736(17)31833-0.

3. Dhital SM. Noncommunicable diseases. N Engl J Med. 2013;369(26):2562. https://doi.org/10.1056/NEJMc 13136 04\%23SA 1 .

4. Naghavi M, Wang H, Lozano R, Davis A, Liang X, Zhou M, et al. Global, regional, and national age-sex specific all-cause and cause-specific mortality for 240 causes of death, 1990-2013: a systematic analysis for the Global Burden of Disease Study 2013. Lancet. 2015;385(9963):117-71. https://doi.org/10.1016/s0140 $-6736(14) 61682-2$.

5. Zhou M, Wang H, Zhu J, Chen W, Wang L, Liu S, et al. Causespecific mortality for 240 causes in China during 1990-2013: a systematic subnational analysis for the Global Burden of Disease Study 2013. Lancet. 2016;387(10015):251-72. https://doi. org/10.1016/s0140-6736(15)00551-6.

6. Liu S, Wu X, Lopez AD, Wang L, Cai Y, Page A, et al. An integrated national mortality surveillance system for death registration and mortality surveillance, China. Bull World Health Org. 2016;94(1):46-57. https://doi.org/10.2471/blt.15.153148.

7. He J, Gu D, Wu X, Reynolds K, Duan X, Yao C, et al. Major causes of death among men and women in China. N Engl J Med. 2005;353(11):1124-34. https://doi.org/10.1056/NEJMsa050467.

8. Sai XY, He Y, Men K, Wang B, Huang JY, Shi QL, et al. Allcause mortality and risk factors in a cohort of retired military male veterans, Xi' an, China: an 18-year follow up study. BMC Public Health. 2007;7:290. https://doi.org/10.1186/1471-2458-7-290.

9. Duan XF, Wu XG, Yu XH, Zheng RP, Li JX, Wang JH, et al. Major causes of death among male steelworkers in Beijing: a prospective study. Zhonghua xin xue guan bing za zhi. 2006;34(7):651-4.

10. Gao X, Hofman A, Hu Y, Lin H, Zhu C, Jeekel J, et al. The Shanghai Changfeng Study: a community-based prospective cohort study of chronic diseases among middle-aged and elderly: objectives and design. Eur J Epidemiol. 2010;25(12):885-93. https:// doi.org/10.1007/s10654-010-9525-6.

11. Lin H, Li Q, Hu Y, Zhu C, Ma H, Gao J, et al. The prevalence of multiple non-communicable diseases among middle-aged and elderly people: the Shanghai Changfeng Study. Eur J Epidemiol. 2016. https://doi.org/10.1007/s10654-016-0219-6.

12. Chen C, Lu FC. The guidelines for prevention and control of overweight and obesity in Chinese adults. Biomed Environ Sci. 2004;17(Suppl):1-36.
13. National High Blood Pressure Education P. The seventh report of the Joint National Committee on prevention, detection, evaluation, and treatment of high blood pressure. Bethesda: National Heart, Lung, and Blood Institute (US); 2004.

14. Adults. JCfDCgoPaToDi. Chinese guidelines on prevention and treatment of dyslipidemia in adults (revision 2016). Chin Circ J. 2016;31(10):937-50. https://doi.org/10.3969/j. issn.1000-3614.2016.10.001.

15. WHO. Definition, diagnosis and classification of diabetes mellitus and its complications: report of a WHO consultation. Part 1: diagnosis and classification of diabetes mellitus. Geneva: WHO; 1999.

16. WHO. Guideline for preclinical evaluation and clinical trials in osteoporosis. Geneva: WHO; 1998.

17. Council PCOotS. Tabulation on the 2010 population census of the peoples republic of China. Beijing: China Statistics Press; 2010.

18. Spiegelman D, Hertzmark E, Wand HC. Point and interval estimates of partial population attributable risks in cohort studies: examples and software. Cancer Causes Control. 2007;18(5):5719. https://doi.org/10.1007/s10552-006-0090-y.

19. Foreman KJ, Marquez N, Dolgert A, Fukutaki K, Fullman N, McGaughey M, et al. Forecasting life expectancy, years of life lost, and all-cause and cause-specific mortality for 250 causes of death: reference and alternative scenarios for 2016-40 for 195 countries and territories. Lancet. 2018;392(10159):2052-90. https ://doi.org/10.1016/s0140-6736(18)31694-5.

20. Chen W, Sun K, Zheng R, Zeng H, Zhang S, Xia C, et al. Cancer incidence and mortality in China, 2014. Chin J Cancer Res. 2018;30(1):1-12. https://doi.org/10.21147/j.i ssn.1000-9604.2018.01.01.

21. Chen W, Zheng R, Zhang S, Zeng H, Xia C, Zuo T, et al. Cancer incidence and mortality in China, 2013. Cancer Lett. 2017;401:63-71. https://doi.org/10.1016/j.canlet.2017.04.024.

22. Gregg EW, Sattar N, Ali MK. The changing face of diabetes complications. Lancet Diabetes Endocrinol. 2016;4(6):537-47. https://doi.org/10.1016/s2213-8587(16)30010-9.

23. Zimmet PZ, Magliano DJ, Herman WH, Shaw JE. Diabetes: a 21 st century challenge. Lancet Diabetes Endocrinol. 2014;2(1):56-64. https://doi.org/10.1016/s2213-8587(13)70112 -8 .

24. Sarwar N, Gao P, Seshasai SR, Gobin R, Kaptoge S, Di Angelantonio E, et al. Diabetes mellitus, fasting blood glucose concentration, and risk of vascular disease: a collaborative meta-analysis of 102 prospective studies. Lancet. 2010;375(9733):2215-22. https ://doi.org/10.1016/s0140-6736(10)60484-9.

25. Giovannucci E, Harlan DM, Archer MC, Bergenstal RM, Gapstur SM, Habel LA, et al. Diabetes and cancer: a consensus report. Diabetes Care. 2010;33(7):1674-85. https://doi.org/10.2337/ dc10-0666.

26. Coughlin SS, Calle EE, Teras LR, Petrelli J, Thun MJ. Diabetes mellitus as a predictor of cancer mortality in a large cohort of US adults. Am J Epidemiol. 2004;159(12):1160-7. https://doi. org/10.1093/aje/kwh161.

27. Gross CP, Guo Z, McAvay GJ, Allore HG, Young M, Tinetti ME. Multimorbidity and survival in older persons with colorectal cancer. J Am Geriatr Soc. 2006;54(12):1898-904. https://doi.org/10. 1111/j.1532-5415.2006.00973.x.

28. (NCD-RisC). NRFC. Worldwide trends in diabetes since 1980: a pooled analysis of 751 population-based studies with 4.4 million participants. Lancet. 2016;387(10027):1513-30. https://doi. org/10.1016/s0140-6736(16)00618-8.

29. Pan XR, Yang WY, Li GW, Liu J. Prevalence of diabetes and its risk factors in China, 1994. National Diabetes Prevention and Control Cooperative Group. Diabetes Care. 1997;20(11):1664-9.

30. Yang W, Lu J, Weng J, Jia W, Ji L, Xiao J, et al. Prevalence of diabetes among men and women in China. $\mathrm{N}$ Engl $\mathrm{J}$ Med. 
2010;362(12):1090-101. https://doi.org/10.1056/NEJMoa0908 292.

31. Xu Y, Wang L, He J, Bi Y, Li M, Wang T, et al. Prevalence and control of diabetes in Chinese adults. JAMA. 2013;310(9):94859. https://doi.org/10.1001/jama.2013.168118.

32. Group, NDR. A mass survey of diabetes mellitus in a population of 300,000 in 14 provinces and municipalities in China (author's transl). Zhonghua nei ke za zhi. 1981;20(11):678-83.

33. Rao Kondapally Seshasai S, Kaptoge S, Thompson A, Di Angelantonio E, Gao P, Sarwar N, et al. Diabetes mellitus, fasting glucose, and risk of cause-specific death. N Engl J Med. 2011;364(9):829-41. https://doi.org/10.1056/nejmoa1008862.

34. Regensteiner JG, Golden S, Huebschmann AG, Barrett-Connor E, Chang AY, Chyun D, et al. Sex differences in the cardiovascular consequences of diabetes mellitus: a scientific statement from the American Heart Association. Circulation. 2015;132(25):2424-47. https://doi.org/10.1161/cir.0000000000000343.

35. Shen C, Schooling CM, Chan WM, Lee SY, Leung GM, Lam TH. Self-reported diabetes and mortality in a prospective Chinese elderly cohort study in Hong Kong. Prev Med. 2014;64:20-6. https://doi.org/10.1016/j.ypmed.2014.03.021.

36. Tajeu GS, Delzell E, Smith W, Arora T, Curtis JR, Saag KG, et al. Death, debility, and destitution following hip fracture. J Gerontol Ser A Biol Sci Med Sci. 2014;69(3):346-53. https://doi. org/10.1093/gerona/glt105.

37. Chen P, Li Z, Hu Y. Prevalence of osteoporosis in China: a meta-analysis and systematic review. BMC Public Health. 2016;16(1):1039. https://doi.org/10.1186/s12889-016-3712-7.

38. Haentjens P, Magaziner J, Colon-Emeric CS, Vanderschueren D, Milisen K, Velkeniers B, et al. Meta-analysis: excess mortality after hip fracture among older women and men. Ann Intern Med. 2010;152(6):380-90. https://doi.org/10.7326/0003-4819-152-6201003160-00008.

39. Lampropoulos CE, Papaioannou I, D'Cruz DP. Osteoporosisa risk factor for cardiovascular disease? Nat Rev Rheumatol. 2012;8(10):587-98. https://doi.org/10.1038/nrrheum.2012.120.
40. Tanko LB, Christiansen C, Cox DA, Geiger MJ, McNabb MA, Cummings SR. Relationship between osteoporosis and cardiovascular disease in postmenopausal women. J Bone Miner Res. 2005;20(11):1912-20. https://doi.org/10.1359/jbmr.050711.

41. Yuan JM, Ross RK, Wang XL, Gao YT, Henderson BE, Yu MC. Morbidity and mortality in relation to cigarette smoking in Shanghai, China. A prospective male cohort study. JAMA. 1996;275(21):1646-50.

42. Lam TH, He Y, Shi QL, Huang JY, Zhang F, Wan ZH, et al. Smoking, quitting, and mortality in a Chinese cohort of retired men. Ann Epidemiol. 2002;12(5):316-20.

43. Li S, Meng L, Chiolero A, Ma C, Xi B. Trends in smoking prevalence and attributable mortality in China, 1991-2011. Prev Med. 2016;93:82-7. https://doi.org/10.1016/j.ypmed.2016.09.027.

44. Organization WH. The world health report 2002-reducing risk, promoting healthy life. Geneva: World Health Organization; 2002.

45. Gu D, He J, Duan X, Reynolds K, Wu X, Chen J, et al. Body weight and mortality among men and women in China. JAMA. 2006;295(7):776-83. https://doi.org/10.1001/jama.295.7.776.

46. Aparicio HJ, Himali JJ, Beiser AS, Davis-Plourde KL, Vasan RS, Kase CS, et al. Overweight, obesity, and survival after stroke in the Framingham Heart Study. J Am Heart Assoc. 2017. https:// doi.org/10.1161/jaha.116.004721.

47. Flegal KM, Kit BK, Orpana H, Graubard BI. Association of all-cause mortality with overweight and obesity using standard body mass index categories: a systematic review and metaanalysis. JAMA. 2013;309(1):71-82. https://doi.org/10.1001/ jama.2012.113905.

Publisher's Note Springer Nature remains neutral with regard to jurisdictional claims in published maps and institutional affiliations. 